\title{
A New Laboratory Designed to Provide an Optimum Environment for Aberration-Corrected Electron Microscopes
}

\author{
L. F. Allard, D. A. Blom, T. A. Nolan, W. H. Sides, L. J. Degenhardt, J. A. Mayo, W. Vogen* \\ and E. St. Romain** \\ Oak Ridge National Laboratory, PO Box 2008, OakRidge, TN 37831-6064 \\ *Vibration Engineering Associates, 4555 Paul Sweet Road, Santa Cruz, CA 95065 \\ **Lord, Aeck \& Sargent, 1201 Peachtree Street, NE Ste 300, Atlanta, GA 30361-3500
}

The next generation of advanced electron microscopes that incorporate aberration correctors for either the illuminating system (i.e. the incident probe for STEM mode) or the objective lens (for conventional TEM imaging) are designed to provide image resolutions well into the sub-angstrom range. The ultimate performance of such instruments, which should achieve sub-angstrom resolution, is critically dependent upon control of environmental influences. Laboratories designed for, or being modified for, housing these instruments must consider construction and operating parameters that were perhaps not as important in older laboratories housing much less critical instruments. Within the next two years, Oak Ridge National Laboratory will house the first 3 aberration-corrected electron microscopes in the nation, and among the first in the world. To accommodate these instruments, a new laboratory is being constructed with the aim of optimizing the environment to allow the ultimate performance specifications of the instruments to be routinely achieved (Fig 1a).

The plans for the new laboratory (working name: Advanced Materials Characterization Laboratory $(\mathrm{AMCL})$ ) have been developed taking into consideration several other laboratory designs or remediations recently described [1-3]. The AMCL will comprise 8 laboratory rooms employing a 'building within a building" design, with a services building directly adjacent (but isolated) that will contain technical offices, a small preparation laboratory, lavatories and a conference/virtual tour" room (Fig. 1b). All HVAC facilities, electrical distribution panels and instrument water chillers will be located on a second floor of that building. Each instrument room has a separate control room to house the remote operation computer system, and also to isolate the instrument environmentally from the influence of the operator(s). A service chase running down the central core of the lab will house the pumps, power supplies, gas tanks and the like. The laboratory has been sited on a parcel of land which has been determined to be seismically very quiet, adjacent to the ORNL High Temperature Materials Laboratory, which will provide support offices and labs. Magnetic fields on the order of several mGauss are present, however, contributed by two overhead 13.8kVA power lines. These fields will be reduced by relocation of the power lines to a nearest approach of $35 \mathrm{~m}$, and by replacing the present widely spaced bare conductors with an "aerial cable" that has the conductors closely spaced to reduce emitted fields. A computation using the software FIELDS [4] indicates that the maximum site-contributed field that should be expected at the nearest microscope location is $0.05 \mathrm{mG}$, just at the adopted specification level. However, all 8 laboratories will be prewired to allow installation of field cancellation devices, should they be required [5]. Other construction parameters include: use of $30 \mathrm{~cm}$ concrete blocks for exterior walls, $20 \mathrm{~cm}$ concrete blocks for interior walls (avoiding the use of metal studs, which can carry current), epoxy-coated rebars in the concrete foundation, no metal plumbing or sprinkler lines, use of plastic races with twisted wires for electrical power, appropriate isolated grounds for the instruments, clean power 
supplied by a motor-generator set housed in the HTML, and air flow in the instrument rooms less than $5 \mathrm{~cm} / \mathrm{sec}$. [6]

\section{References:}

[1] J. H. Turner, M. A. O'Keefe and R. Mueller, in 55th Ann. Proc. MSA, (1997) 1177-1178

[2] H. Lichte et al., 59th Ann. Proc. MSA, (2001) 894-895, Micros \& Microanalysis 7, suppl.2

[3] D. A. Muller and J. Grazul, J Elect Microsc 50 (3): 219-226 2001

[4] FIELDS 1.0 program, Southern California Edison, Irwindale, CA (contactauthor for details)

[5] Spicer Consulting, 'http://Www.spicerconsulting.com'

[6] Planning and Construction provided by Department of Energy, Office of Science Landlord General Plant Project funds for Oak Ridge National Laboratory, operated by UT-Battelle, LLC

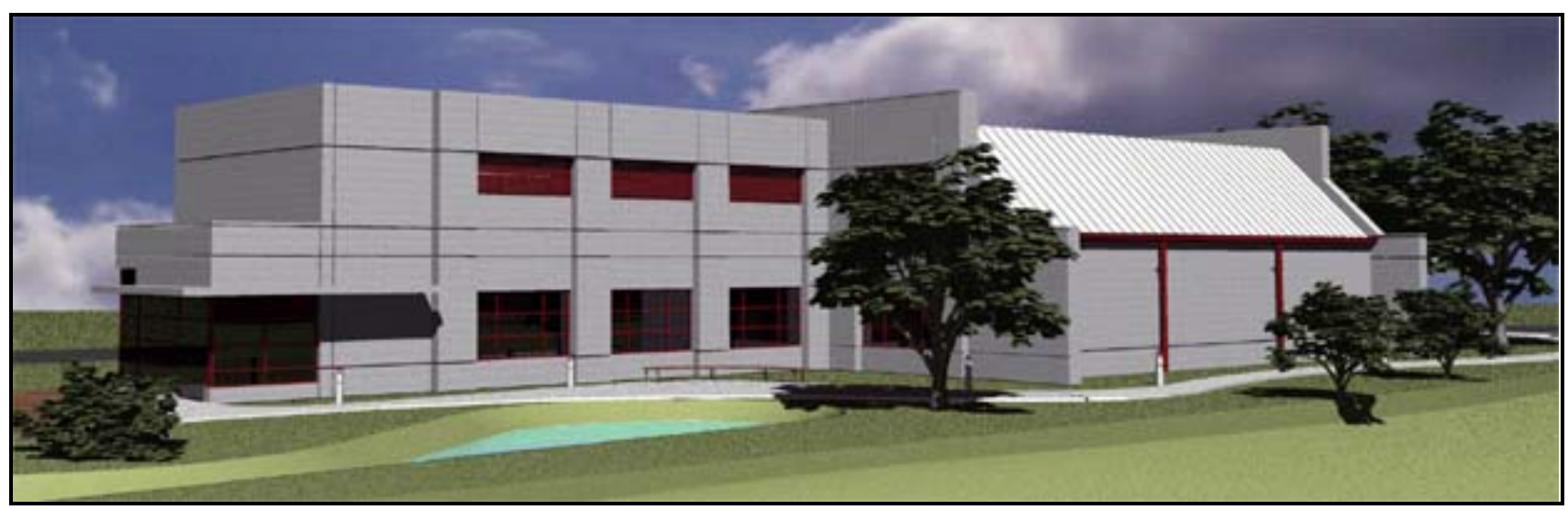

FIG. 1 Artist's rendering of the ORNL Advanced Materials Characterization Laboratory building.

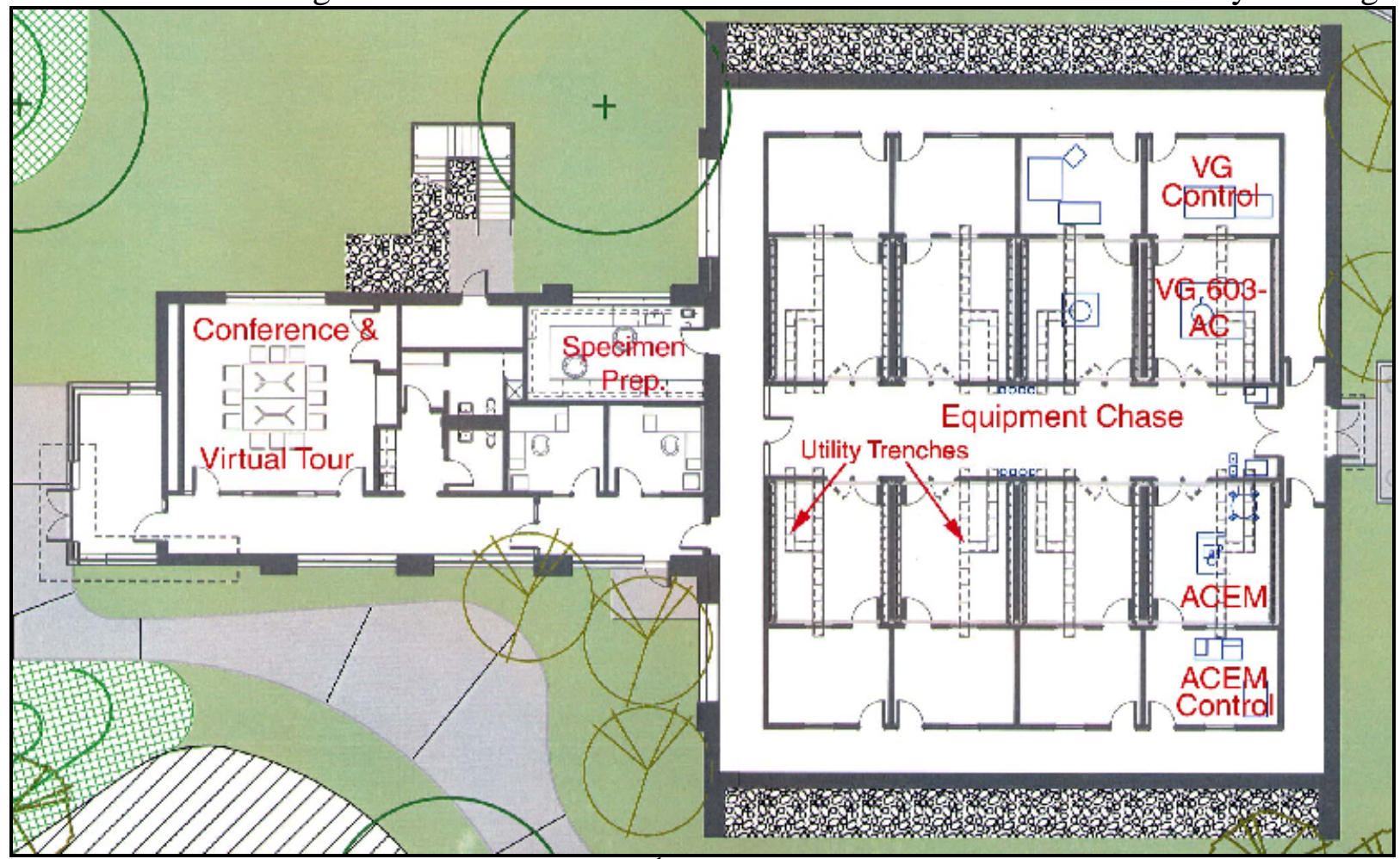

FIG. 2 Floor plan for the new laboratory ( $2^{\text {nd }}$ floor HVAC not shown). 